\title{
The impact of biological variation on postharvest population dynamics
}

\author{
Maarten L.A.T.M. Hertog * \\ Fresh Technologies, Institute of Food Nutrition and Human Health, Massey University, Private Bag 11 222, \\ Palmerston North, New Zealand
}

Received 19 October 2001; accepted 13 March 2002

\begin{abstract}
This paper outlines a mathematical approach to the interpretation of postharvest batch behaviour based on the underlying processes occurring at the level of the individual food items and on the amount of biological variation present. This technique opens the door to a mechanistic interpretation of postharvest batch behaviour, both qualitative and quantitative, enabling the postharvest industries to improve their control of the quality of their produce throughout the postharvest chain. The generic approach is outlined and applied to case studies on shrivelling of 'Braeburn' apples, the colour change of 'Hass' avocados and stress crack development in corn grains. (C) 2002 Elsevier Science B.V. All rights reserved.
\end{abstract}

Keywords: Modelling; Biological variation; Postharvest batch behaviour; Shrivel of apple; Colour of avocado; Cracking of corn grain

\section{Introduction}

Postharvest treatment of horticulture crops aims at prolonging shelf life. The end of the commercial shelf life of individual produce items is reached when the limiting quality attribute reaches its critical level for acceptance (Tijskens, 1995; Sloof et al., 1996). If all individual items in a batch were identical they would all reach the critical limit at the same moment and the whole batch would become instantly unacceptable. However, because of biological variation, this is

\footnotetext{
* Tel.: + 64-6-350-5986; fax: + 64-6-350-5610

E-mail address: m.1.hertog@massey.ac.nz (M.L.A.T.M. Her$\operatorname{tog})$.
}

not the case with some items becoming unacceptable either earlier or later. The percentage of unacceptable fruit over time sigmoidally increases from 0 to $100 \%$ with the slope of the curve relating to the amount of biological variation within the batch. A very homogenous population will show a very steep curve, while a heterogeneous population will have a shallow curve. Often, this behaviour can be properly described using the symmetric logistic function (Tijskens et al., 1996; Hertog et al., 1999). In other cases, the sigmoidal curve is not symmetric (Bertolini and Tian, 1996) or never reaches 100\% (Sarwar and Kunze, 1989; van der Sman et al., 1996). Results like these trigger the awareness that, to fully understand the behaviour at the population level, 
we need to go back to the level of the individual items involved. The exact shape of the sigmoidal curve describing the population behaviour will depend on the underlying physiological mechanism dictating the relationship between shelf life and the product property (or properties) subject to biological variation.

This paper presents a generic analytic approach to model the type of population dynamics outlined here, explicitly taking into account the underlying mechanism. The technique will be illustrated using the case of shrivelling of 'Braeburn' apples, the colour change of avocados and stress crack development in corn grains.

\section{Generic modelling approach}

It is assumed that the rejection or acceptance of individual items in a batch is based on some biology-based quality aspect $(Q)$ whose behaviour as a function of time $(t)$ can be described using some mechanistic model (Fig. 1A). Furthermore, some product property $(p)$ is identified as being the main source of biological variation in determining the quality $Q$. The mechanistic model is now defined as $Q(t, p)$. The individual items will be rejected once their quality reaches the limit for acceptance $\left(Q_{\text {lim }}\right)$ at the end of their shelf life $\left(t_{\text {shelf }} ;\right.$ Fig. $\left.1 \mathrm{~A}\right)$. By solving $Q(t, p)$ for $t_{\text {shelf }}, t_{\text {shelf }}$ can be defined as a function of $Q_{\lim }$ and $p$ (resulting in: $t_{\text {shelf }}\left(p, Q_{\text {lim }}\right)$; Fig. 1B).

When dealing with a batch, there is not one single value for $p$, but a whole distribution of $p$-values (Fig. 2A). Using the function $t_{\text {shelf }}(p$, $\left.Q_{\text {lim }}\right)$ the distribution of $p$-values can be transformed into a distribution of corresponding $t_{\text {shelf }}$ values (Fig. 2A). This frequency distribution $f\left(t_{\text {shelf }}\right)$ defines how many items will subsequently reach $Q_{\lim }$ given the value of $p$ for each item. The cumulative frequency distribution of $t_{\text {shelf }}$ $\left(F\left(t_{\text {shelf }}\right)\right)$ describes what percentage of the batch reached $Q_{\text {lim }}$ as a function of time. This sigmoidal curve results from the transformation of the cumulative frequency distribution of $p$, again using the function $t_{\text {shelf }}\left(p, Q_{\text {lim }}\right)$ to do the transformation (Fig. 2B). This $F\left(t_{\text {shelf }}\right)$ is the desired relationship describing the percentage of unacceptable items over time incorporating the underlying mechanism describing how and why the items do become unacceptable. This whole procedure has to be conducted for each new mechanism studied and the result in terms of $F\left(t_{\text {shelf }}\right)$ will strongly depend on the mechanism studied.

Assuming a normal distribution of product property $p$ defined by its average $\left(\mu_{p}\right)$ and its standard deviation (S.D.; $\sigma_{p}$ ), the cumulative normal distribution of $p$ given by $F(p)$, will be symmetric. If the transform function $t_{\text {shelf }}\left(p, Q_{\text {lim }}\right)$ is linear (Fig. 3A), the distribution of $t_{\text {shelf }}$ will be
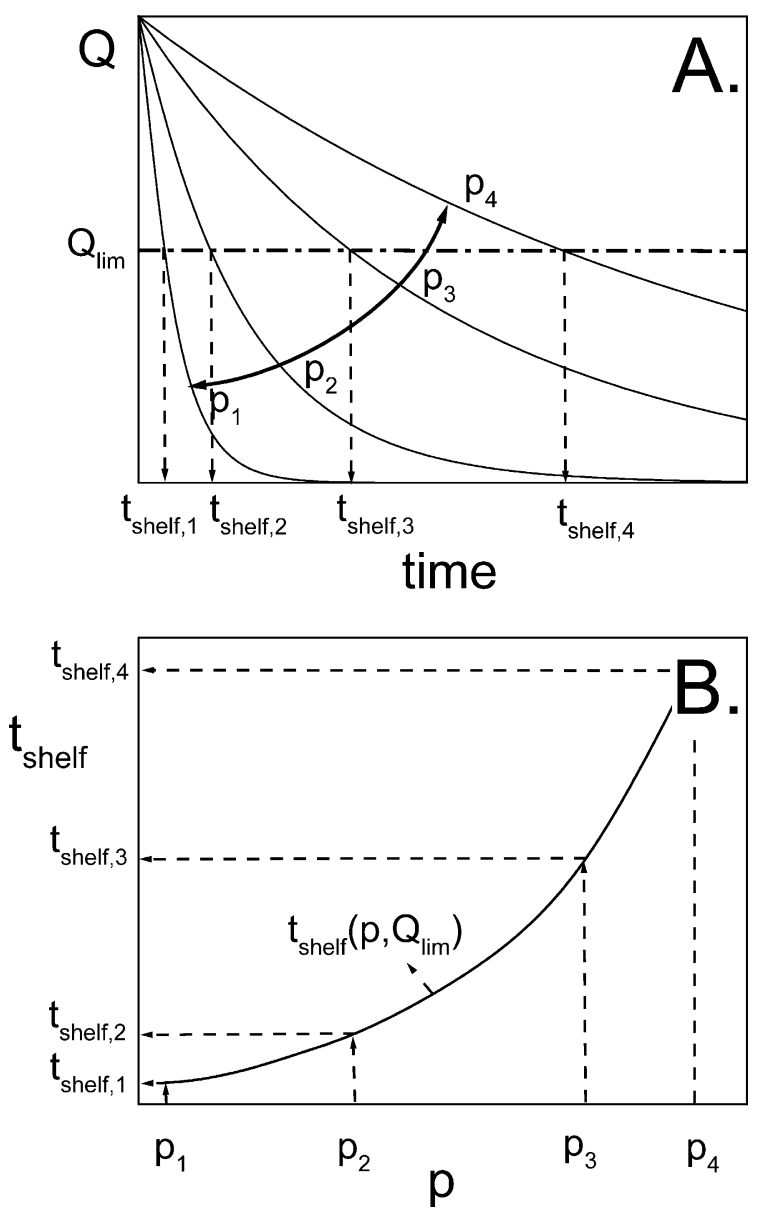

Fig. 1. This figure visualises how the shelf life $\left(t_{\text {shelf }}\right)$ of an imaginary product based on quality attribute $Q$ depends on the limit of acceptance $\left(Q_{\mathrm{lim}}\right)$ and some product property $(p)$ being the main source of biological variation (Fig. 1A). This function $\left(t_{\text {shelf }}\left(p, Q_{\text {lim }}\right)\right)$ can be used to find the corresponding $t_{\text {shelf }}$ for a given value of $p$ (Fig. 1B). 

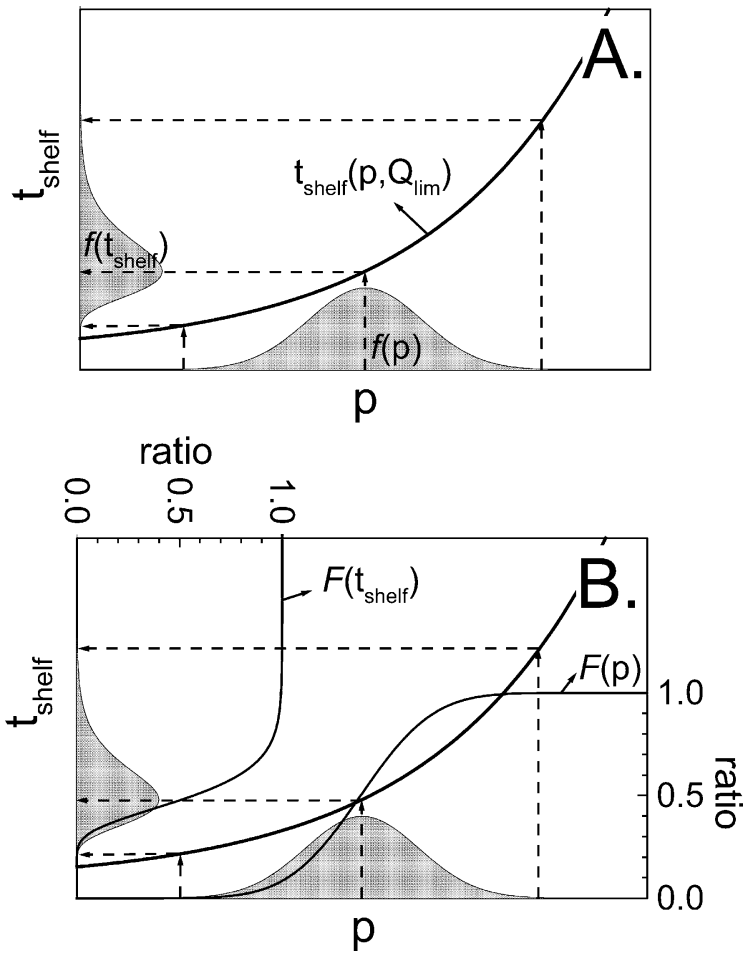

Fig. 2. When dealing with a batch, each item has its own value for $p$, resulting in a whole frequency distribution of $p$-values $(f(p))$. Using the function $t_{\text {shelf }}\left(p, Q_{\text {lim }}\right)$ this distribution of $p$-values can be transformed in the corresponding distribution of $t_{\text {shelf }}$-values ( $f\left(t_{\text {shelf }}\right)$; Fig. 2A). In the same way, the cumulative frequency distribution for $p(F(p))$ can be transformed in the cumulative frequency distribution of $t_{\text {shelf }}\left(F\left(t_{\text {shelf }}\right)\right.$; Fig. 2B) describing the percentage of items becoming unacceptable during time.

normal as well and the cumulative distribution $F\left(t_{\text {shelf }}\right)$ is again symmetric. In all other cases the resulting distribution of $t_{\text {shelf }}$ will be skewed, resulting in an asymmetric $F\left(t_{\text {shelf }}\right)$ (Fig. 2B). In the case where the transform function is monotonously increasing (Fig. 3A, Fig. 2B), the resulting $F\left(t_{\text {shelf }}\right)$ can be used directly. In the case of a monotonously decreasing transform function, $1-F\left(t_{\text {shelf }}\right)$ should be used to correct for the inversion imposed by the transform function (Fig. 3B).

Theoretically, the approach can be applied for any given distribution of $p$ as long as the analytical solution of the corresponding cumulative distribution exists. However, even for the normal distribution (Eq. (1)) there is no analytic solution for its cumulative distribution.

$f(x)=\frac{1}{\sigma \cdot \sqrt{2 \pi}} \mathrm{e}^{-(1 / 2)((x-\mu) / \sigma)^{2}}$

Generally, the logistic binomial function for proportions (Eq. (2)) is recognised as a good approximation of the cumulative normal distribution with $x=a / b$ indicating the inflection point corresponding to the population average $\mu$, and the parameter $b$ being related to the S.D. $\sigma$ (Bollen, 1993; Brown and Rothery, 1993).
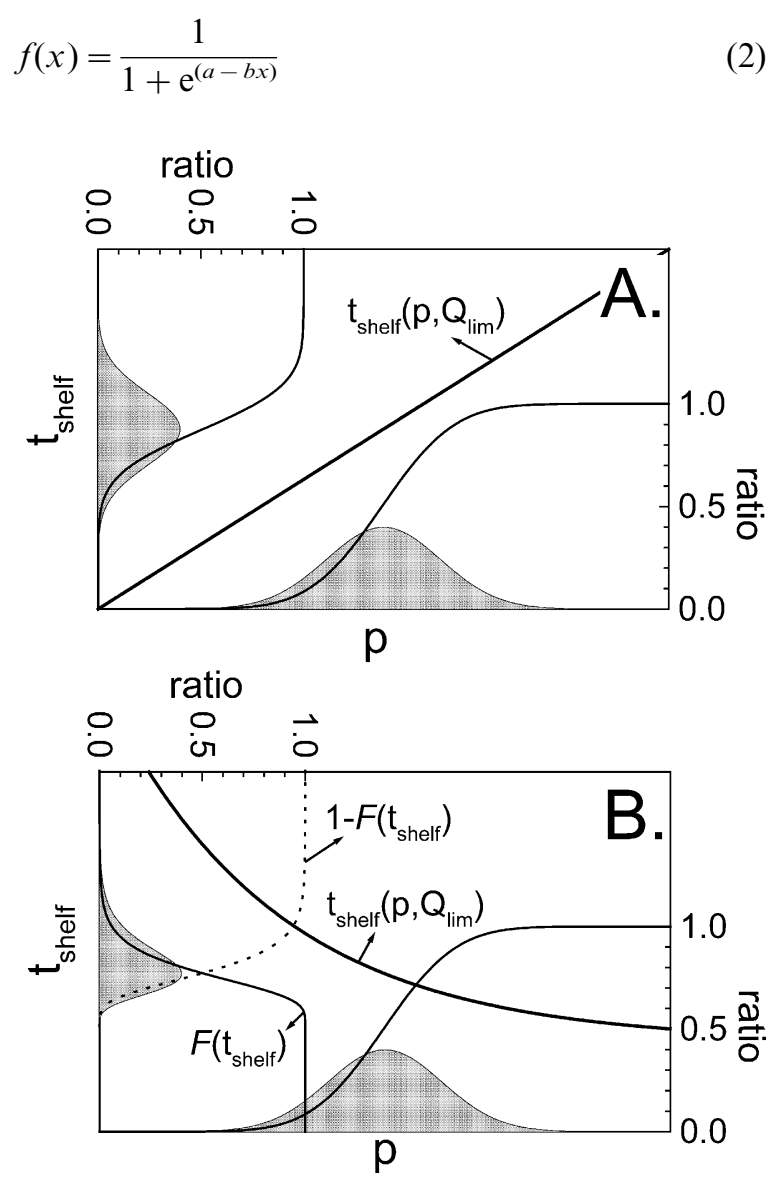

Fig. 3. See Fig. 2, but now with a linear monotonously increasing relationship between shelf life and the variable product property $p$ (Fig. 3A) and a non-linear monotonously decreasing relation between shelf life and the variable product property $p$ (Fig. 3B). In this last case $1-F\left(t_{\text {shelf }}\right)$ should be used to correct for the inversion imposed by the transform function. 


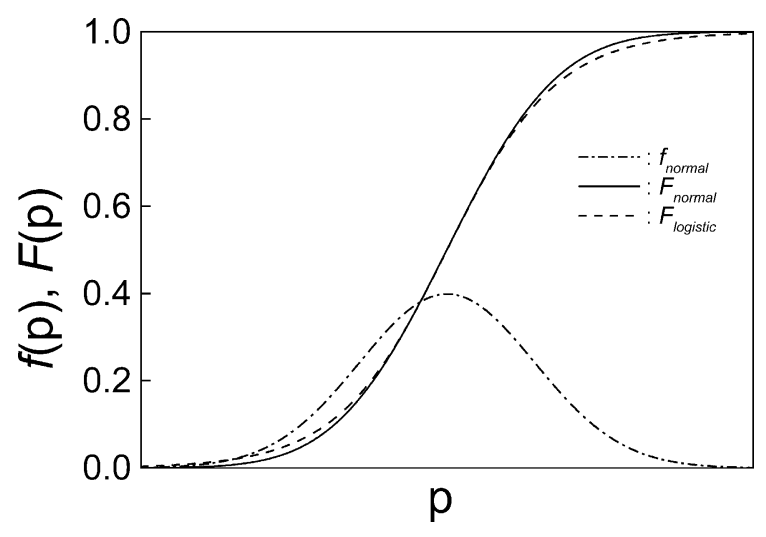

Fig. 4. Graphical comparison between the cumulative normal distribution (-) based on the normal frequency distribution $(-\cdot-$; Eq. (1)) and the approximation based on the logistic function (---; Eq. (3)) using the same values for $\mu$ and $\sigma$.

To see how the parameter $b$ relates to the S.D., the derivative of the logistic equation was compared with the normal distribution for $a /$ $b=\mu$. The two functions agree when $b=2 \sqrt{ } 2 /$ $\sigma \sqrt{ } \pi$. Combining Eq. (2) with these two relationships that describe how $a$ and $b$ relate to $\mu$ and $\sigma$, resulted in the following approximation of the cumulative normal distribution:

$F(x) \approx \frac{1}{1+\mathrm{e}^{2 \sqrt{2}(\mu-x) / \sigma \sqrt{\pi}}}$

A graphical evaluation (Fig. 4) showed that although the match between the normal distribution and the approximation based on the logistic function is not exact, the two are close enough to suit our purpose. To illustrate how to apply and to show the added value of the approach outlined above, it will be applied to a number of cases of increasing complexity.

\section{Shrivelling of apple}

During storage, apples lose weight through transpiration and respiration (Maguire et al., 2001). Once weight loss of apples increases to about $3-10 \%$, shrivel (visible wrinkling of the fruit skin) occurs. There are high levels of variability in the levels of weight loss and the devel- opment of shrivel among individual apples and grower lines (Maguire et al., 2000). The large variation in water vapour permeance $\left(P_{\mathrm{H}_{2} \mathrm{O}}^{\prime}\right.$ in mol s$\left.{ }^{-1} \mathrm{~m}^{-2} \mathrm{~Pa}^{-1}\right)$ of the fruit skin is assumed to be the most important source of variation responsible for the variability of incidence of shrivel (Maguire et al., 1999, 2001). Shrivelling of a batch of apples can be modelled based on a mechanistic approach describing the weight loss of individual apples, assuming that the fruit-to-fruit variation is solely due to the variation in water vapour permeance.

\subsection{Modelling weight loss of individual apples}

Transpiration by fruits involves the diffusion of water from the fruit into the surrounding atmosphere and can be described using the two dimensional steady state solution of Fick's first law of diffusion (Maguire et al., 2001):

$r_{\mathrm{H}_{2} \mathrm{O}}^{\prime}=P_{\mathrm{H}_{2} \mathrm{O}}^{\prime} \cdot A \cdot \Delta p_{\mathrm{H}_{2} \mathrm{O}}$

with, $r_{\mathrm{H}_{2} \mathrm{O}}^{\prime}$ is the rate of water loss from the whole system $\left(\mathrm{mol} \mathrm{s}^{-1}\right), A$ is the surface area of the fruit $\left(\mathrm{m}^{2}\right)$ and $\Delta p_{\mathrm{H}_{2} \mathrm{O}}$ is the difference in partial pressure of water vapour between the environment and the inside of the fruit $(\mathrm{Pa})$. The weight loss resulting from transpiration is directly proportional to the molecular weight of water $\left(M_{\mathrm{H}_{2} \mathrm{O}}, 0.018 \mathrm{~kg} \mathrm{~mol}^{-1}\right)$. The weight loss resulting from respiration $\left(r_{\mathrm{CO}}, \mathrm{mol} \mathrm{kg}^{-1} \mathrm{~s}^{-1}\right)$ is proportional to the molecular weight of carbon $\left(M_{\mathrm{C}}, 0.012 \mathrm{~kg} \mathrm{~mol}^{-1}\right)$ and the initial weight of the product $\left(M_{0}, \mathrm{~kg}\right)$. Together this results in an overall weight loss of:

$\frac{\mathrm{d} M}{\mathrm{~d} t}=-P_{\mathrm{H}_{2} \mathrm{O}}^{\prime} \cdot A \cdot \Delta p_{\mathrm{H}_{2} \mathrm{O}} \cdot M_{\mathrm{H}_{2} \mathrm{O}}-r_{\mathrm{CO}_{2}} \cdot M_{0} \cdot M_{\mathrm{C}}$

Assuming constant environmental conditions (temperature and atmospheric composition), respiration by the product can be treated as constant. The resulting analytic solution describing how, under constant environmental conditions, the weight of an individual fruit linearly decreases with time is given by Eq. (6): 


$$
\begin{aligned}
M(t)= & M_{0}-t \cdot\left(P_{\mathrm{H}_{2} \mathrm{O}}^{\prime} \cdot A \cdot \Delta p_{\mathrm{H}_{2} \mathrm{O}} \cdot M_{\mathrm{H}_{2} \mathrm{O}}\right. \\
& \left.+r_{\mathrm{CO}_{2}} \cdot M_{0} \cdot M_{\mathrm{C}}\right)
\end{aligned}
$$

The weight loss of a typical 'Braeburn' apple during storage under ambient air at $0.5^{\circ} \mathrm{C}$ is depicted in Fig. 5A. Shrivelling is assumed to occur at time $t_{\text {shrivel }}$, when the mass is reduced to $95 \%$ of its initial mass $\left(M_{0.95}\right.$; Maguire et al., 2000).

\subsection{Incorporating fruit-to-fruit variation}

As apples are generally sorted according to count size, resulting in batches of homogeneously sized fruit, skin permeance to water is the main source of fruit-to-fruit variation. The rate of weight loss will vary depending on the actual value of $P_{\mathrm{H}_{2} \mathrm{O}}^{\prime}$ resulting in different times $\left(t_{\text {shrivel }}\right)$ at which the fruit will reach their critical value $\left(M_{0.95}\right)$. Solving Eq. (6) for $t=t_{\text {shrivel }}$ results in a function describing the time an apple will take to shrivel as a function of its $P_{\mathrm{H}_{2} \mathrm{O}}^{\prime}$ (Eq. (7); Fig. 5B) within a batch of apples, the $P_{\mathrm{H}_{2} \mathrm{O}}^{\prime}$ is practically normally distributed (Maguire, pers. comm.).

$$
t_{\text {shrivel }}=\frac{M_{0}-M_{0.95}}{P_{\mathrm{H}_{2} \mathrm{O}}^{\prime} \cdot A \cdot \Delta p_{\mathrm{H}_{2} \mathrm{O}} \cdot M_{\mathrm{H}_{2} \mathrm{O}}+r_{\mathrm{CO}_{2}} \cdot M_{0} \cdot M_{\mathrm{C}}}
$$

Thus, the incidence of shrivel in a batch of apples as a function of time can be described using the approach outlined above. This can be done by transforming the cumulative normal distribution of $P_{\mathrm{H}_{2} \mathrm{O}}^{\prime}$ (given by Eq. (3)) using Eq. (7). To perform this transformation, Eq. (7) has to be solved for $P_{\mathrm{H}_{2} \mathrm{O}}^{\prime}$ and substituted for $x$ into Eq. (3) with $\mu$ and $\sigma$ now referring to the average and S.D. of $P_{\mathrm{H}_{2} \mathrm{O}}^{\prime}$. As, in this case, the transform function (Eq. (7)) is monotonously decreasing, $1-F\left(t_{\text {shelf }}\right)$ should be used to correct for the inversion imposed by the transform function resulting in:
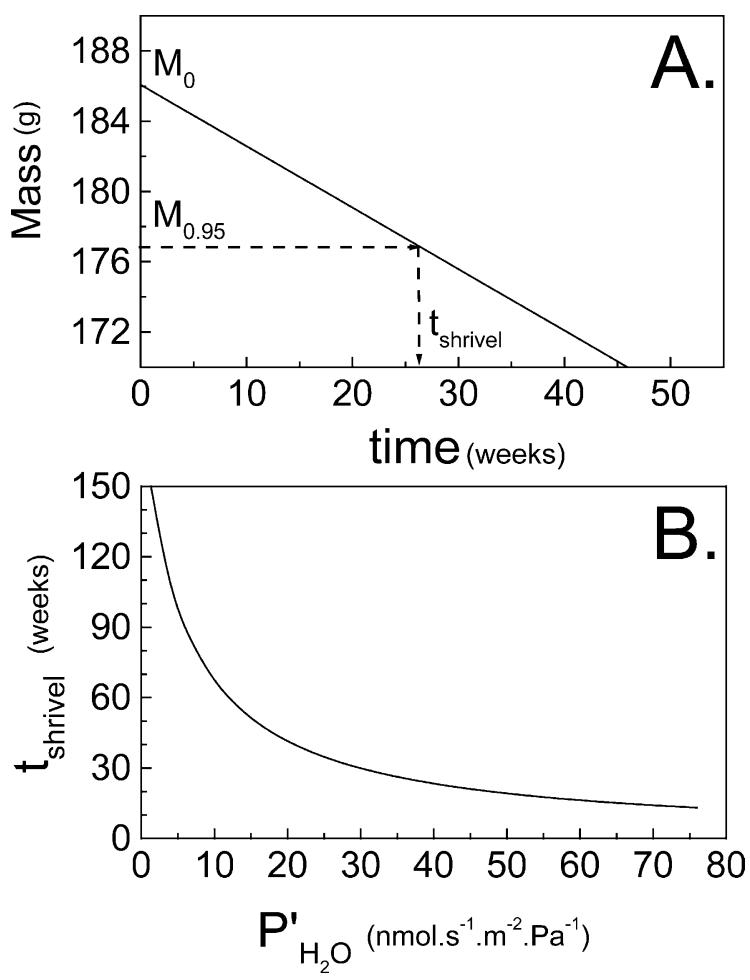

Fig. 5. Weight loss of a typical 'Braeburn' apple during storage under ambient air at $0.5{ }^{\circ} \mathrm{C}$ and $93.5 \%$ RH (Fig. 5A). Shelf life is limited by shrivelling, occurring at $t_{\text {shrivel }}$ when the fruit mass is reduced to about $95 \%$ of its initial weight $\left(M_{0.95}\right.$ as compared with $M_{0}$ ). This time to shrivel is highly variable and depends on the water vapour permeance of the fruit $\left(P_{\mathrm{H}_{2} \mathrm{O}}^{\prime}\right.$; Fig. 5B).

describing what percentage of the fruit in the batch incurred shrivel due to a weight loss exceeding $5 \%$ of the initial weight. Eq. (8) was used to predict the shrivelling of 35 different grower lines of 'Braeburn' apples. Each grower line consisted of 500 fruit with an average fruit mass of $M_{0}=$ $0.186 \mathrm{~kg}$ an average fruit area of $A=0.018 \mathrm{~m}^{2}$ (estimated according to Clayton et al., 1995) and storage under air at $0.5{ }^{\circ} \mathrm{C}$ and $93.5 \% \mathrm{RH}$ $\left(\Delta p_{\mathrm{H}_{2} \mathrm{O}}=41.0 \mathrm{~Pa}\right)$. The respiration rate $\left(r_{\mathrm{CO}_{2}}\right)$ at

$\operatorname{Shrivel}(t)=1-\frac{1}{1+\mathrm{e}^{2 \cdot \sqrt{2} \cdot\left(\mu-\left(M_{0}-M_{0.95}-r_{\mathrm{CO}_{2}} \cdot M_{0} \cdot M_{\mathrm{C}} \cdot t\right) / t \cdot A \cdot \Delta p_{\mathrm{H}_{2} \mathrm{O}} \cdot M_{\mathrm{H}_{2} \mathrm{O}}\right) / \sigma \cdot \sqrt{\pi}}}$

This equation can be used to predict the shrivel incidence in batches of apple fruit over time,
$0.5{ }^{\circ} \mathrm{C}$ was set to $34.1 \mathrm{E}-9$ mol. $\mathrm{kg}^{-1} \cdot \mathrm{s}^{-1}$ (Hertog et al., 2001). Water vapour permeance $\left(P_{\mathrm{H}_{2} \mathrm{O}}^{\prime}\right)$ of 


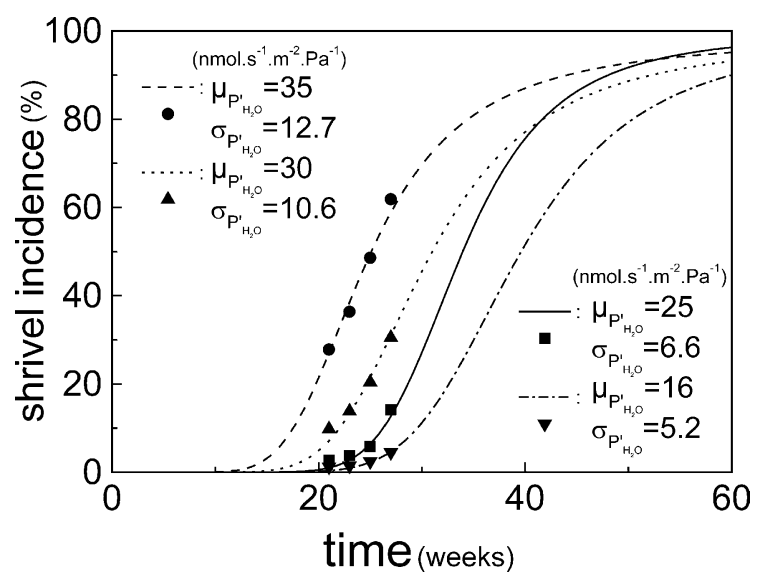

Fig. 6. Shrivel incidence for four batches of 'Braeburn' apples (500 fruit per grower line) stored under air at $0.5{ }^{\circ} \mathrm{C}$ and $93.5 \% \mathrm{RH}$. The data points are the observed shrivel scores. The model predictions (lines) are calculated using Eq. (8) and are based on the average $P_{\mathrm{H}_{2} \mathrm{O}}^{\prime}$ and their S.D. as measured independently for each of the grower lines.

each individual fruit was measured as described in Maguire et al. (2000). The model predictions for the shrivel incidence of the 35 batches (Fig. 6) were based on the average $P_{\mathrm{H}_{2} \mathrm{O}}^{\prime}$ and their S.D. as measured on the individual fruit. When comparing the model predictions to the experimental data, there was a close agreement between the two. Some of the variation not accounted for was due to variation in other factors than $P_{\mathrm{H}_{2} \mathrm{O}}^{\prime}$, such as the exact humidity in the different storage facilities, variation in respiratory activity, fruit size, surface area and weight loss until shrivel. Fig. 6 compares the results for four grower lines that had distinctly different average $P_{\mathrm{H}_{2} \mathrm{O}}^{\prime}$ values and different levels of fruit-to-fruit variation. Together these account for the position and the shape of the logistic curve describing the batch behaviour of shrivelling 'Braeburn' fruit. It should be emphasised that the simulated lines (Fig. 6) were not fitted to the observed shrivel incidence data but are real predictions based on the withinbatch variation in $P_{\mathrm{H}_{2} \mathrm{O}}^{\prime}$ values and the above mentioned values of the other model parameters.

\subsection{Benefits}

Even though the process of deriving the final model equation may appear to be complex the advantages of this approach over fitting some general asymmetric sigmoidal equation are numerous. Each of the model parameters has a clear meaning as they are founded on underlying physical and physiological processes. As the model is based on a generally accepted mechanistic approach, the model can easily be used to account, for instance, for the effect of temperature (poten-tially affecting both average permeance and res-piration rate), the effect of modified atmospheres (via the humidity effect on driving force for water loss and via oxygen and carbon dioxide levels on their effect on respiration rate) or the effect of reducing the variation by sorting batches of fruit into different storage lines according to their permeance.

\section{Colour change in avocado}

'Haas' avocado fruit are harvested at an immature green stage. Skin colour changes reflect the ripening of the fruit. Due to biological variation in maturity at harvest, an apparently initial homogeneous batch of green fruit can result in a very heterogeneous batch of still green and already coloured fruit. For the industry it will be important to either sort these fruit at an early stage into more homogeneous batches, or to be able to predict when a certain batch will have reached a certain critical level of ripening.

With avocados, the fruit-to-fruit variation in colour development (Fig. 7) could not be directly related to the initial green skin colour. To identify the source of variation between individual avocados due to variation in maturity, a more sophisticated approach was needed. Colour change of 140 avocado fruit (cv Hass) stored at $7{ }^{\circ} \mathrm{C}$ was measured as hue values using a chromameter and analysed using a logistic model to identify the main source of variation in terms of the model parameters. Subsequently, batch behaviour for avocados, in terms of the percentage of fruit coloured to a certain critical level, was deduced based on the developed model. 


\subsection{Modelling colour change of individual avocados}

Tijskens and Evelo (1994) modelled the colour change of tomatoes using a logistic curve. With tomatoes changing from green to red, the $a$ and $b$ values measured in the Hunter system increased with time. Ripening avocados that turn from green to black resulted in hue values $(H)$ decreasing over time (Fig. 7). To allow for this, the model formulation from Tijskens and Evelo (1994) was slightly adapted resulting in:

$$
H(t)=H_{+\infty}+\frac{H_{-\infty}-H_{+\infty}}{1+\mathrm{e}^{k \cdot t}\left(H_{-\infty}-H_{0}\right) /\left(H_{0}-H_{+\infty}\right)}
$$

describing hue ( $H$ in $\left.{ }^{\circ}\right)$ over time ( $t$ in days) as a function of the two asymptotic hue values $\left(H_{+\infty}\right.$ and $H_{-\infty}$, both in ${ }^{\circ}$ ) at plus and minus infinite time, the rate constant $k\left(\mathrm{day}^{-1}\right)$ and the initial hue value $H_{0}\left({ }^{\circ}\right)$.

In applying models to different fruit, batches or cultivars, it is worthwhile to consider what parameters can be assumed to be either in common for a particular fruit species or cultivar or specific for a particular batch or cultivar (Tijskens and Evelo, 1994; Hertog et al., 1997; Schouten and Van Kooten, 1998; Tijskens et al., 1998; Hertog et al., 1999). Preliminary analysis revealed

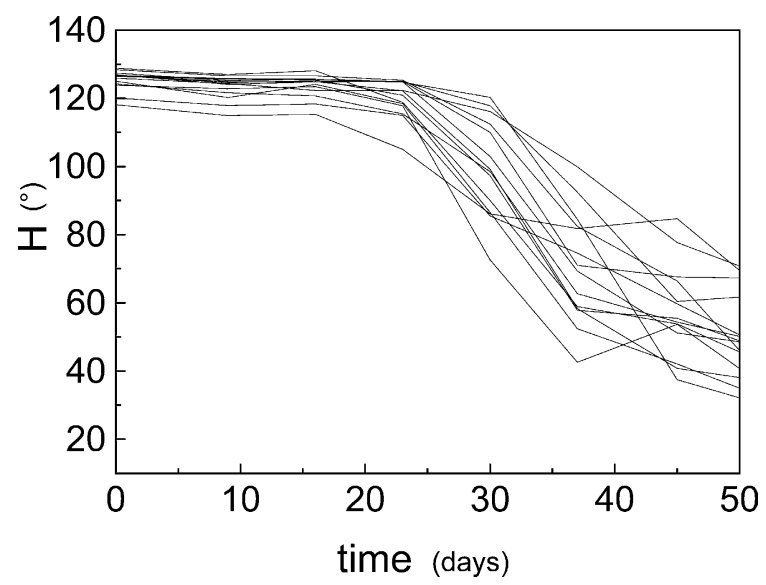

Fig. 7. Colour change of 'Hass' avocados stored in air at $7{ }^{\circ} \mathrm{C}$. Colour was measured as hue value $\left(H\right.$ in $\left.^{\circ}\right)$. The figure shows a representative sub-sample of the 140 individual fruit measured. that the rate constant $k$ could be treated as a constant $\left(k=0.213\right.$ day $\left.^{-1}\right)$ for all avocados measured.

As not all avocados reached their final constant end hue value $\left(H_{+\infty}\right)$ within the time span of the experiment this model parameter was not unambiguously defined for all avocados. However, forcing one common $H_{+\infty}$ value $\left(H_{+\infty}=35^{\circ}\right)$ upon the avocados did not noticeably reduce the statistical accuracy of the model fit. The change in hue of individual avocados could still be described with explained parts of over $97 \%$. The assumption of a common $H_{+\infty}$ value seems to be justifiable, assuming that all avocados ripen to a comparable intense purple/black colour.

The model parameter most important in determining the variation between individual avocados was the initial hue $H_{0}$ relative to its minus infinite value $\left(H_{-\infty}\right)$. Fruit showing a delayed colour change had a $H_{0}$ close to $H_{-\infty}$. The smaller $H_{0}$ relative to $H_{-\infty}$ the earlier the colour of the fruit changed. The model parameter $H_{0}$ was set to the measured initial hue value. As a result, the only model parameter left to define the observed fruitto-fruit variation was $H_{-\infty}$. To include the relativity of $H_{0}$ to $H_{-\infty}$ the latter was defined in terms of the first by introducing:

$H_{-\infty}=(1+C) H_{0}$

Instead of estimating $H_{-\infty}$ directly, the parameter $C$ was estimated for each of the 140 individual avocados by fitting the combined Eqs. (9) and (10) to the experimental colour change data. This resulted in a distribution of $C$-values characterising the fruit-to-fruit variation in the batch of avocados measured (Fig. 8A). The parameter $C$ can be interpreted as a maturity index, indicating the biological age of that particular avocado.

\subsection{Incorporating fruit-to-fruit variation}

As the model parameter $C$ is characterising the observed fruit-to-fruit variation this information can be used to determine the batch behaviour of ripening avocados in terms of the percentage of fruit coloured to a certain critical hue level. Depending on the actual value of $C$, avocados will 

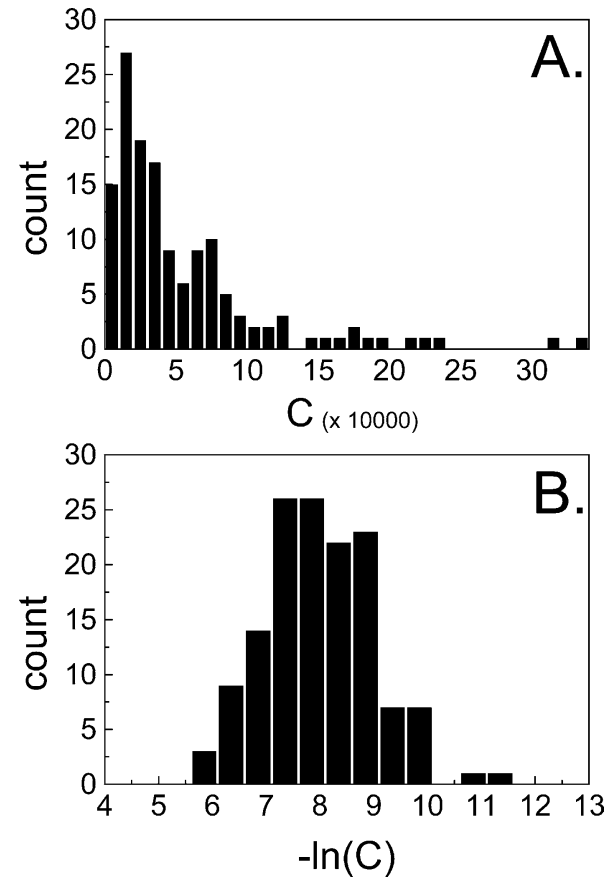

Fig. 8. Frequency distribution of model parameter $C$ (Fig. 8A) and of its normal logarithmic transformed values (Fig. 8B). Parameter $\mathrm{C}$ can be interpreted as a maturity index.

take different times to ripen $\left(t_{\text {ripen }}\right)$ to a critical hue value $\left(H_{\text {crit }}\right)$. Combining Eqs. $(9)$ and (10) and solving for $t=t_{\text {ripen }}$ resulted in a function describing the time an avocado will take to ripen as a function of its $C$-value (Eq. (11)):

$$
\begin{aligned}
& t_{\text {ripen }}= \\
& \frac{\ln \left(\left(H_{0}-H_{+\infty}\right)\left(H_{\text {crit }}-H_{0} \cdot(1+C)\right) / H_{0} \cdot C \cdot\left(H_{+\infty}-H_{\text {crit }}\right)\right)}{k}
\end{aligned}
$$

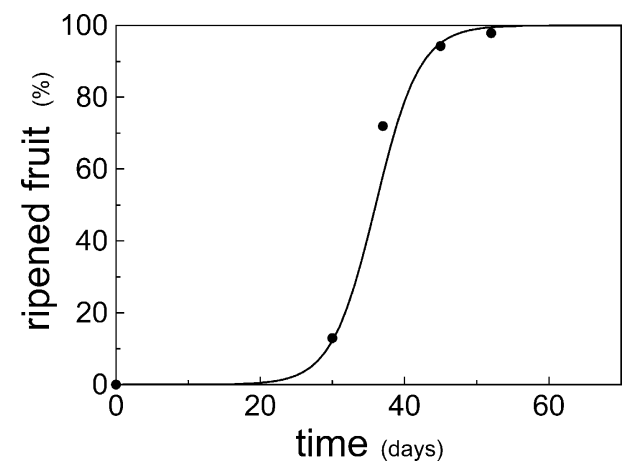

Fig. 9. Ripening of a batch of 'Hass' avocados expressed as the percentage fruit that reached a critical hue value of $80^{\circ}$. The data points represent the observed batch behaviour of the fruit. The model predictions (lines) are calculated using Eq. (12) and are based on the observed average $C^{\prime}$ and its S.D. (Fig. 8).

describing the percentage of avocados in a batch ripened to a certain critical hue value as a function of time, can be generated by transforming the cumulative normal distribution of $C^{\prime}$ (given by Eq. (3)) using Eq. (11). To perform this transformation, Eq. (11) has to be solved for $C$ and, after applying a normal logarithmic transformation to get an expression for $C^{\prime}$, substituted for $x$ into Eq. (3) with $\mu$ and $\sigma$ now referring to the average and S.D. of the transformed $C^{\prime}$ values. As, in this case, the final transform function (Eq. (11) in terms of $C^{\prime}$ instead of $C$ ) is monotonously increasing, no further correction is needed, resulting in:

$\operatorname{Ripen}(t)=\frac{1}{1+\mathrm{e}^{2} \cdot \sqrt{2} \cdot\left(\mu+\ln \left(\left(H_{0}-H_{\text {crit }}\right) \cdot\left(H_{+\infty}-H_{0}\right) / H_{0} \cdot\left(e^{t \cdot k} \cdot\left(H_{+\infty}-H_{\text {crit }}\right)+H_{0}-H_{+\infty}\right)\right)\right) / \sigma \cdot \sqrt{\pi}}$

One requisite of the developed approach is that the variable causing the biological variation should follow a normal distribution. As can be seen from Fig. 8A, the distribution of $C$ did not comply with this. However, after applying a normal logarithmic transformation $\left(C^{\prime}=-\ln (C)\right.$, the resulting $C^{\prime}$ values were normally distributed (Fig. 8B).

The cumulative distribution of $t_{\text {ripen }}\left(F\left(t_{\text {ripen }}\right)\right)$,
The final model from Eq. (12) was used to describe the batch behaviour of the measured avocados (Fig. 9). In this example an arbitrarily critical hue value $\left(H_{\text {crit }}\right)$ of $80^{\circ}$ was used. However, the model could be used with any value of a $H_{\text {crit }}$ depending on specific requirements the avocado industry might have. Again, it should be emphasised that the model prediction from Fig. 9 was not fitted to the observed data but is a real 
prediction based on the within batch variation of $C^{\prime}$-values.

\subsection{Benefits}

Even though it looks a long way round to get to the sigmoidal curve from Fig. 9, applying the developed technique opens the door to an improved interpretation of the observed batch behaviour of avocados. If, for instance, the effect of temperature on the rate constant $k$ for individual fruit is known, the effect of temperature on a whole batch of fruit can be extrapolated from there. Once the source of variation is identified and linked to some physiological property of the product, at-harvest characterisations can be used to predict the divergent behaviour of batches further down the logistic chain resulting in sophisticated harvest strategies with respect to harvest time and the allocation of batches to different purposes.

\section{Stress crack development in corn grains}

Finally, the developed technique was applied to develop a qualitative conceptual model to an ultimate batch problem, the development of stress cracks in corn grains. This was the case study that triggered the development of the outlined approach. However, because of its complexity and the lack of data and expert knowledge to validate this model, this example will not be discussed in detail.

One of the main quality problems with corn is the development of stress cracks after drying. The level of cracking (single or multiple cracks) affects the breakage susceptibility of the grains when subjected to impact force during handling and transport (Gunasekaran and Muthukumarappan, 1993). The development of stress cracks is generally believed to be related to tension developing within the grain due to moisture and temperature gradients induced by drying, tempering and cooling (Litchfield and Okos, 1988) and are affected by factors like temperature, humidity, and time. Work by Kim (2000) revealed that the stress crack development in a batch of corn grains was related to the average size of the grains. Small grains showed less severe cracking than larger grains. Furthermore, the sigmoidal curve describing the percentage of grains with multiple cracks over time was not symmetric.

\subsection{Conceptual model}

A simple conceptual model was developed assuming two compartments in a corn grain, a core and a shell. The core exchanges moisture with the surrounding shell, while the shell also exchanges moisture with the surrounding air, all described using Fick's first law of diffusion. During drying and depending on the drying conditions, a moisture gradient is generated between core and shell. The stress incurred was defined as the integral of this moisture difference between core and shell, thus incorporating the combined effects of time, temperature and humidity during drying. The incurred stress is affected by the size of the grain, as large grains will take longer to dry and thus result in more stress accumulating. Cracking was assumed to occur as soon as the stress exceeded a certain critical level. By combining this qualitative description of stress developing in individual grains with the outlined population approach, the effect of biological variation in grain size on the batch behaviour of corn grains was studied using hypothetical parameter values for the model.

The observed model behaviour (Fig. 10) agreed very well with the typical development of stress cracking as observed for various size and shape categories for four different corn hybrids as described by Kim (2000). The percentage of intact grains rapidly decreased as the corn grains started to develop single cracks. During time the grains with single cracks started to develop multiple cracks resulting in a decrease in the percentage of grains with single cracks in favour of an increasing percentage of grains showing multiple cracks. Given certain drying conditions, the level of grains with severe multiple cracking depended on the average grain size. A batch with, on average, large grains ended up with $100 \%$ of the grains showing multiple cracks (Fig. 10A). A batch with, on average, smaller grains ended up with less than $100 \%$ of the grains showing multiple cracks (Fig. 


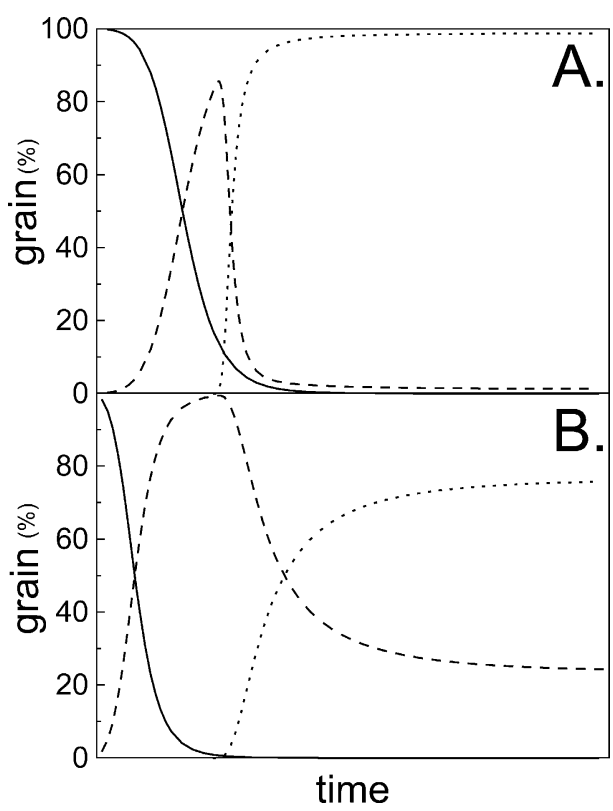

Fig. 10. Model output of the qualitative conceptual model describing stress cracking during drying of batches with, in average, large (Fig. 10A) or small (Fig. 10B) corn grains. The model describes the percentage of intact grains (-), the percentage of grains showing single cracks (---) and the percentage of grains developing severe multiple cracks (…).

10B). This example highlights two different aspects of biological variation, namely the clearly asymmetric population behaviour in terms of the percentage of grains developing multiple cracks, and the fact that the population is not necessarily going to $100 \%$ incidence.

\subsection{Benefits}

As the model is based on the physics of drying, it incorporates the effects of time, temperature and $\mathrm{RH}$ throughout the whole drying process, and, therefore, directly links into the important process control parameters of grain drying. If this model on the cracking of grain can be validated, it will enable the grain industry to optimise the drying process for the different batches of grains, minimising the current losses related to cracking of the grain.

\section{Conclusions}

When trying to identify the source of variation one should always realise that rate constants in kinetic models are by definition constant as they are a property of the system involved. However, apparent rates can vary between individual items due to, for instance, differences in concentrations of substrate or enzyme available. In the case of shrivel in apple, the diffusion rate constant of water in air stays constant, but due to structural variation in the skin individual apples have different values for their water vapour permeance (which is in fact an apparent rate). Again in the case of stress cracking of corn grain it is not the diffusion rate constant of water vapour that is varying between individual grains, but the size of the grain resulting in different lengths of the diffusion pathway of water. In the case of avocados, the rate of colour change is treated as a real constant and the variation is coming from the variation in the relative initial colour (which can be considered as a substrate). This stresses the importance of a sound decomposition of the problem to allow correct identification of the source of variation.

The developed approach can be applied to a wide range of postharvest issues such as colour and texture changes, occurrence of physiological disorders, or rots due to microbial infection. This extension of a mechanistic modelling approach to include biological variation enhances the understanding of batch dynamics, which is of a great commercial value to the horticulture industries.

The outlined approach differs from techniques based on repeated model runs with varying parameters, in that it is less computationally by intensive and that it is describing the acceptability of a batch instead of setting confidence intervals to the average fruit behaviour.

\section{Acknowledgements}

The author wishes to express his thanks to Anneke-Thea Hertog for inspiring discussions, and Kate Maguire for providing the background information on the shrivelling of 'Braeburn' apples. Also thanks to Bruce MacKay and Pol Tijskens for critically reading the manuscript. This work was developed within the framework of a project funded by the New Zealand Foundation 
for Research, Science and Technology (MAUAX008).

\section{References}

Bertolini, P., Tian, S.P., 1996. Low-temperature biology and pathogenicity of Penicillium hirsutum on garlic in storage. Postharvest Biol. Technol. 7, 83-89.

Bollen, F., 1993. Determination of the probability of bruising. Proceedings of the Australasian Postharvest Conference, 219-223.

Brown, D., Rothery, P., 1993. Models in Biology: Mathematics, Statistics and Computing. Wiley, England, p. 688.

Clayton, M., Amos, N.D., Banks, N.H., Morton, R.H., 1995. Estimation of apple fruit surface area. New Zealand J. Crop. Hort. Sci. 23, 345-349.

Gunasekaran, S., Muthukumarappan, K., 1993. Breakage susceptibility of corn of different stress-crack categories. Trans. ASAE 36, 1445-1446.

Hertog, M.L.A.T.M., Boerrigter, H.A.M., Boogaard, G.J.P.M., van den Tijskens, L.M.M., van Schaik, A.C.R., 1999. Predicting keeping quality of strawberries (cv. 'Elsanta') packed under modified atmospheres: an integrated model approach. Postharvest Biol. Technol. 15, 1-12.

Hertog, M.L.A.T.M., Nicholson, S.E., Banks, N.H., 2001. The effect of modified atmospheres on the rate of firmness change in 'Braeburn' apples. Postharvest Biol. Technol. 23, $175-184$.

Hertog, M.L.A.T.M., Tijskens, L.M.M., Hak, P.S., 1997. On the effects of temperature and senescence on the accumulation of reducing sugars during storage of potato (Solanum tuberosum L.) tubers. Postharvest Biol. Technol. 10, 67-79.

Kim, T.H., 2000. Physical changes in maize (Zea mays L.) grains during postharvest drying. (PhD Thesis) Massey University, Palmerston North, New Zealand.

Litchfield, J.B., Okos, M.R., 1988. Prediction of corn kernel stress and breakage induced by drying, tempering, and cooling. Trans. ASAE 31, 585-594.
Maguire, K.M., Banks, N.H., Lang, A., Gordan, I., 2000. Harvest date, cultivar, orchard, and tree effects on water vapour permeance in apples. J. Am. Soc. Hort. Sci. 125, $100-104$.

Maguire, K.M., Banks, N.H., Lang, A., 1999. Sources of variation in water vapour permeance of apple fruit. Postharvest Biol. Technol. 17, 11-17.

Maguire, K.M., Banks, N.H., Opara, L.U., 2001. Factors affecting weight loss of apples. Hort. Rev. 25, 197-234.

Sarwar, G., Kunze, O.R., 1989. Relative humidity increases that cause stress cracks in corn. Trans. ASAE 32, 17371743.

Schouten, R.E., Van Kooten, O., 1998. Keeping Quality of cucumber batches: is it predictable. Acta Hort. 476, 349355.

Sloof, M., Tijskens, L.M.M., Wilkinson, E.C., 1996. Concepts for modelling the quality of perishable products. Trends Food Sci. Technol. 7, 165-171.

van der Sman, R.G.M., Evelo, R.G., Wilkinson, E.C., van Doorn, W.G., 1996. Quality loss in packed rose flowers due to Botrytis cinerea infection as related to temperature regimes and packaging design. Postharvest Biol. Technol. 7, 341-350.

Tijskens, L.M.M., Evelo, R.G., 1994. Modelling colour of tomatoes during postharvest storage. Postharvest Biol. Technol. 4, 85-98.

Tijskens, L.M.M., 1995. A generic model on keeping quality of horticultural products, including influences of temperature, initial quality and quality acceptance limits. In: Proceeding of 19th International Congress Refrigeration, 1995, The Hague, vol. 2, pp. 361-368 The Netherlands.

Tijskens, L.M.M., Sloof, M., Wilkinson, E.C., van Doorn, W.G., 1996. A model on the effects of temperature and time on the acceptability of potted plants stored in darkness. Postharvest Biol. Technol. 8, 293-305.

Tijskens, L.M.M., Hertog, M.L.A.T.M., Van Dijk, C., 1998. Generic modelling and practical applications. In: Nicolaï, B.M., de Baerdemaeker, J. (Eds.), Proceedings COST 915 \& Copernicus CIPA-CT94-0120 Workshop on Food Quality Modelling. European Commission, Brussels, pp. 145151. 